\title{
INTERVENÇÃO ANALÍTICO-COMPORTAMENTAL DIRIGIDA A FAMILIARES DE PORTADORES DO TRANSTORNO OBSESSIVO-COMPULSIVO
}

\section{AN ANALYTIC-BEHAVIOR INTERVENTION DIRECTED TO RELATIVES OF PATIENTS WITH OBSESSIVE COMPULSIVE DISORDER}

LILIAN BOARATI - ORCID 0000-0002-7424-9680

FANI ETA KORN MALERBI - ORCID 0000-0002-0514-5597

Pontifícia Universidade Católica de SÃo PAULo, BRASIL

\begin{abstract}
RESUMO
O presente estudo teve como objetivo avaliar um procedimento de intervenção dirigido a mães de portadores de Transtorno Obsessivo Compulsivo (TOC) com vistas a reduzir a acomodação familiar. Participaram três díades compostas de adultos portadores do TOC e suas mães. Inicialmente, foram realizadas entrevistas individuais com cada participante com o objetivo de listar os rituais apresentados pelos portadores e as respostas de acomodação familiar. Posteriormente, cada mãe foi instruída a registrar diariamente os rituais de seus filhos que solicitavam sua participação e as suas respostas de acomodação. A análise desses registros permitiu que as pesquisadoras classificassem as respostas de acomodação das mães em ordem crescente de frequência e instruíssem cada mãe a colocar em extinção, primeiramente, as solicitações menos frequentes de participação nos rituais e reforçar qualquer outra classe de respostas diferente das ritualísticas (DRO). Uma vez eliminada uma classe de respostas ritualísticas, as mães eram instruídas a focalizar a classe seguinte e assim sucessivamente. Foram realizados de 13 a 14 encontros semanais com cada mãe. Em cada encontro, as mães recebiam instruções sobre como proceder e eram orientandas a enfrentar as dificuldades que apareciam na realização da tarefa. Trinta por cento dos registros foram também analisados por um observador independente resultando em $90,6 \%$ de concordância. Os principais resultados evidenciaram a eliminação da maioria das respostas de acomodação apresentadas pelas três mães.
\end{abstract}

Palavras-chave: análise do comportamento, família, extinção, comportamento obsessivo-compulsivo.

\begin{abstract}
The objective of the present study was to evaluate an intervention addressed to mothers of patients with Obsessive Compulsive Disorder (OCD) in order to reduce family accommodation. Participants were three dyads composed of adults with OCD and their mothers. Initially, interviews were conducted separately with each participant in order to detect the rituals presented by the patients and family accommodation. Subsequently, each mother was instructed to daily record the ritualistic responses of their children requesting their participation and their accommodation responses. The analysis of mothers' records allowed the researchers to classify the accommodation responses in ascending order of frequency and to instruct mothers to extinguish first the less frequent requests for participation in the rituals and to reinforce any other class of ritualistic responses (DRO). Once a class of accommodation responses was suppressed, the mothers were instructed to focus on the next class and so on. Thirteen to 14 weekly meetings only with the mothers occurred. In each meeting, the mothers were instructed on how to proceed and how to cope with the difficulties faced in the accomplishment of the task. Thirty percent of the records were also analyzed by an independent observer resulting in $90.6 \%$ of agreement. The main results showed the elimination of most accommodation responses presented by the three mothers.
\end{abstract}

Key words: behavior analysis, family, extinction, obsessive-compulsive behavior.

$\overline{\text { Correspondência referente }}$ a este artigo deve ser enviada a Lilian Boarati (lilianboarati@hotmail.com) ou Fani Malerbi (fanimalerbi@gmail.com).

DOI. 10.18542/rebac.v14i1.7158 
De acordo com o Manual Diagnóstico e Estatístico de Transtornos Mentais 5 (DSM-5), o Transtorno Obsessivo Compulsivo (TOC) é um transtorno crônico, classificado na categoria Transtornos ObsessivoCompulsivos Relacionados ("obsessive-compulsive related disorders") definido pela presença de obsessões e/ou compulsões (American Psychiatric Association, 2014). Esse manual caracteriza as obsessões como pensamentos, impulsos ou imagens recorrentes e persistentes que em algum momento são experimentados como intrusivos e indesejados e que, na maioria dos indivíduos, causam acentuada ansiedade ou sofrimento. $\mathrm{O}$ portador de TOC tenta suprimir ou ignorar as obsessões ou neutralizá-las com outro pensamento ou ação. As obsessões podem ser categorizadas como: (1) obsessões de conteúdo de agressão, sexo ou religião; (2) obsessões de simetria e/ou ordenação; (3) obsessões de limpeza e contaminação e (4) obsessões de colecionismo.

Segundo o DSM-5, as compulsões são definidas por comportamentos repetitivos evidentes como lavar as mãos, organizar, verificar, colecionar, etc., ou privados como orar, contar ou repetir palavras em silêncio, "trocar" um pensamento "mau" por um pensamento "bom", de agressividade, etc., em resposta a uma obsessão ou de acordo com regras que devem ser rigidamente aplicadas. Esses comportamentos supostamente visam prevenir ou reduzir a ansiedade ou evitar algum evento temido. Entretanto, esses comportamentos não parecem ter uma conexão realista com o que supostamente visam evitar ou são claramente excessivos. As compulsões podem ser categorizadas nas dimensões: (1) limpeza (lavar compulsivo das mãos, do corpo, do cabelo, escovar compulsivamente os dentes, etc.); (2) verificação, conferência e reasseguramento (verificar repetidas vezes a tranca das portas, o acendedor do fogão, conferir repetidamente uma informação, etc.); (3) ordenação e arrumação (enfileirar objetos, arrumar compulsivamente de acordo com critérios próprios); (4) contagem (contar um determinado número de vezes, contar coisas, contar números ímpares, etc.) e (5) simetria e lateralidade (arrumar objetos, encostar em coisas de forma simétrica, etc.).

A prevalência internacional do TOC está entre $1,1 \%$ a $1,8 \%$ da população geral e varia nas diversas faixas etárias, sendo o sexo feminino mais afetado quando comparado ao sexo masculino na idade adulta (DSM-5). Um estudo realizado no Brasil por Oliveira, Silva, Teles e Machado (2012) mostrou que aproximadamente 2,5\% da população são portadores de TOC e destes $10 \%$ ficam gravemente incapacitados pela doença.

De acordo com Torres et al. (2011), o tratamento do TOC baseia-se em intervenções farmacológicas, psicológicas e educacionais. O’Connor et al. (2006) enfatizam que não se deve esperar remissão completa dos sintomas do TOC apenas com o tratamento farmacológico, fazendo-se necessário associar a psicoterapia e intervenções educativas com os familiares dos pacientes com TOC.

Segundo Skinner (1992, 2000), para que um psicoterapeuta possa compreender, predizer e controlar o comportamento de seu paciente é necessário identificar as variáveis responsáveis pela sua instalação e manutenção. Para esse autor qualquer comportamento está sob o controle do ambiente atual e passado do indivíduo que se comporta. As respostas que os indivíduos apresentam produzem alterações no ambiente que, por sua vez, modificam o indivíduo alterando a probabilidade de que respostas semelhantes venham a ocorrer no futuro.

$\mathrm{O}$ analista do comportamento avalia como insuficiente a análise topográfica das respostas apresentadas pelos portadores de transtornos mentais para realizar seu trabalho terapêutico e considera que esta deve ser complementada com a análise das contingências de reforçamento responsáveis pela instalação e manutenção do comportamento do paciente.

Segundo Wielenska (2001), as contingências de reforçamento que descrevem o comportamento de portadores do TOC envolvem principalmente o reforçamento negativo. No reforçamento negativo, ocorre o fortalecimento de respostas que têm como consequência o adiamento, a suspenção ou a eliminação de estímulos aversivos. Para essa autora, a manutenção e o fortalecimento das obsessões e das compulsões do portador do TOC estão relacionados a uma diminuição da ansiedade ou da angústia que geralmente ocorre após a apresentação dos rituais. Porém, posteriormente, frente a um crescente desconforto, as respostas de fuga e esquiva que caracterizam as compulsões são novamente apresentadas, cada vez mais elaboradas, gerando novamente um alívio daqueles sentimentos. Wielenska (2001) sugere que após a realização da análise funcional das respostas obsessivo-compulsivas, deve-se empregar a técnica de exposição com prevenção de respostas (EPR) e instruir o portador para que apresente respostas alternativas aos seus rituais, considerando que se o paciente correr os riscos que as respostas ritualísticas supostamente evitam, expondo-se à situação supostamente aversiva, poderá assegurar-se de que os riscos não são reais. Essa autora ainda ressalta que esta exposição gera subprodutos como, por exemplo, emoções intensas produzidas pela forma não obsessiva de contato com o mundo, ou seja, estas exposições aos estímulos temidos colocam o indivíduo numa situação em que ele próprio deverá avaliar seus medos, desconfortos físicos, perigos ou ameaças reais presentes no ambiente. Também considera importante que o terapeuta analítico comportamental incentive a pessoa a enfrentar tais exposições, para que ela possa apresentar comportamentos apropriados e deixar de empregar os recursos patológicos utilizados com o objetivo de se sentir bem. Com os progressos da exposição, o indivíduo poderá descobrir que o forte sofrimento desaparece lentamente sem a apresentação de seus rituais.

Com base na observação de pacientes, Calvocoressi et al. (1995) e Steketee (1997) verificaram que o TOC, em geral, interfere no funcionamento familiar, levando os membros da família a modificarem suas rotinas em função dos sintomas do portador. De acordo com Calvocoressi et al. (1995) em 88,2\% dos casos do TOC há a participação da família nos sintomas do TOC. 
Para Guedes (2001) quando os familiares do portador de TOC não têm as informações relevantes sobre esse transtorno apresentam ações pouco ou nada adequadas, as quais podem intensificar e manter os rituais, uma vez que, neste cenário, os comportamentos dos familiares costumam ser inconsistentes e intermitentes. Em alguns momentos a família atende às solicitações do portador, participando direta ou indiretamente de seus rituais, em outros ignora tais solicitações e em outras ocasiões pune o comportamento do portador. De acordo com essa autora, este padrão familiar mantém e fortalece os rituais do portador, tornando-os resistentes à extinção.

Para Murray-Swank e Dixon (2004) a educação dos familiares facilita a aceitação do tratamento do TOC e o engajamento de todos os envolvidos no processo terapêutico do portador. Os estudos realizados por Murray-Swank e Dixon (2004) e por Renshaw, Steketee e Chambless (2005) com familiares de portadores do TOC concluíram que após intervenções psicoeducativas os familiares passaram a compreender melhor o transtorno e suas causas e aprenderam estratégias efetivas para manejar os sintomas do paciente. De acordo com esses autores, quando os familiares aprendem como devem se comportar, eles deixam de reforçar os comportamentos compulsivos e colaboram efetivamente para o tratamento do portador.

Diversos autores têm pesquisado o envolvimento dos familiares nos rituais apresentados pelo portador do TOC e denominam este envolvimento de acomodação familiar. Trata-se de um conjunto de comportamentos apresentados pelos familiares que participam dos rituais, direta ou indiretamente, contribuindo para que o portador de TOC siga as regras rígidas que o transtorno impõe.

Muitos estudos têm apresentado dados que indicam que a acomodação familiar pode ser um fator de manutenção dos sintomas obsessivo-compulsivos (Albert et al., 2010; Calvocoressi et al., 1995; Cooper, 1996; Ferrão \& Florão, 2010; Gomes et al., 2014; Guedes, 1997; Pardue et al., 2014; Ramos-Cerqueira, Torres, Torresan, Negreiros, \& Vitorino, 2008; Steketee \& Van Noppen, 2003; Thompson-Hollands, Abramovitch, Tompson, \& Barlow, 2015; Torres et. al., 2011). Os estudos de Ferrão e Florão (2010), Gomes et al. (2014) e de Ramos-Cerqueira et al. (2008) sugeriram que o nível de acomodação familiar pode estar relacionado com a gravidade dos sintomas obsessivo-compulsivos.

Diferentes métodos têm sido utilizados para avaliar a acomodação familiar com o objetivo de conhecer suas dimensões, variáveis de controle, tipos, efeitos e intervenções terapêuticas para a redução deste fenômeno. Calvocoressi et al. (1995) desenvolveram um instrumento de avaliação deste envolvimento que recebeu o nome de Escala de Acomodação Familiar (FAS). A versão de 1995 foi traduzida para o Português e adaptada por Guedes para o nosso meio (Guedes, 1997). Posteriormente, Gomes, Meyer, Braga, Kristensen, \& Cordioli (2010) traduziram e adaptaram a Escala para o português, recebendo o nome FAS-IR

O presente estudo teve como objetivo avaliar os efeitos de uma intervenção analítico-comportamental dirigida a mães de adultos com TOC no enfraquecimento das respostas de acomodação familiar avaliados tanto pela FAS-IR quanto pelos dados produzidos por um registro diário realizado pelas mães .

\section{Participantes}

\section{MÉTODO}

Foram convidados a participar da presente pesquisa três díades compostas por um adulto portador de TOC com rituais compulsivos e um familiar que apresentava acomodação familiar, selecionados a partir de entrevistas com familiares que acompanhavam os portadores de TOC na consulta com o psiquiatra no Serviço de Ambulatório do Transtorno ObsessivoCompulsivo (PROTOC) do Instituto de Psiquiatria - IPqHCFMUSP, entre Novembro de 2014 e Fevereiro de 2015.

Os critérios de inclusão dos familiares nesta pesquisa foram: (1) ter um familiar adulto portador de TOC, diagnosticado de acordo com o CID-10 (Organização Mundial da Saúde, 1997) ou DSM-5 (American Psychiatric Association, 2014), apresentando rituais compulsivos; (2) ter disponibilidade para encontros semanais com a primeira autora por um período de 16 semanas; (3) relatar episódios de acomodação familiar na Entrevista Inicial confirmados pela Escala FAS-IR; (4) ter a idade mínima de 18 anos e (5) residir na mesma casa que o portador. Excluíram-se os familiares que cuidavam de outra pessoa doente, que apresentavam demência, psicose ou retardo mental.

Os critérios de inclusão dos portadores do TOC nesta pesquisa foram: (1) ter a idade mínima de 18 anos e ser portador do TOC com compulsões, diagnosticado de acordo com o CID-10 ou DSM-5 por um psiquiatra do PROTOC; (2) já ter envolvido o familiar nos rituais do TOC; (3) declarar que aceitava que o familiar participasse da pesquisa, após ser informado que o objetivo do estudo era orientar o seu familiar a respeito dos seus comportamentos obsessivo-compulsivos. O critério de exclusão dos portadores foi apresentar comorbidades psiquiátricas graves, exceto depressão, investigadas na Entrevista Inicial. A descrição das três díades é apresentada a seguir:

Díade 1. O portador 1 (P1) do sexo feminino tinha 27 anos de idade no início do estudo, solteira, não trabalhava, era dependente da mãe para sair de casa e alimentar-se. Recebeu o diagnóstico de TOC aos 21 anos de idade. Os rituais compulsivos nos quais P1 solicitava a participação de sua mãe eram: (1) pedir para lavar suas roupas separadamente das roupas dos outros familiares, (2) pedir para preparar o almoço e o jantar em panela separada daquela usada para o preparo das refeições da família e (3) pedir para pegar e guardar bebidas e alimentos armazenados na geladeira. Sua mãe (F1) tinha 67 anos no início do estudo, era dona de casa, viúva com quatro filhos, sendo P1 a filha caçula e única com TOC. A mãe relatou que por sete anos, diariamente, várias vezes ao dia, atendeu a todas as solicitações acima descritas por acreditar que assim estava ajudando sua filha no tratamento do TOC.

Díade 2. O portador $2(\mathrm{P} 2)$ do sexo masculino tinha 32 anos de idade no início do estudo, era solteiro, graduado 
em administração, trabalhava, praticava esportes regularmente e era vocalista de uma banda de rock. Recebeu o diagnóstico do TOC aos 18 anos de idade. Os rituais compulsivos em que P2 solicitava a participação de sua mãe eram: (1) pedir para reassegurar que seus pensamentos obsessivos sobre Deus, religião e doença estavam corretos; (2) abraçar e beijar a mãe após ter pensamentos obsessivos sobre a morte dela; (3) pedir para que ela dormisse junto com ele no mesmo quarto ou no mesmo colchão e (4) perguntar várias vezes ao dia se a mãe estava bem. Sua mãe (F2) tinha 61 anos no início do estudo, era dona de casa, viúva com dois filhos, sendo P2 o mais velho e único da família com TOC. A mãe relatou que por 14 anos, diariamente, várias vezes ao dia, atendeu a todas as solicitações acima descritas por acreditar que agindo dessa forma fazia com que P2 ficasse menos ansioso, angustiado ou agitado.

Díade 3. O portador 3 (P3) era do sexo feminino, tinha 27 anos de idade no início do estudo, solteira e trabalhava. Recebeu o diagnóstico do TOC aos 15 anos de idade. Os rituais compulsivos em que P3 solicitava a participação de seus familiares (pai, mãe ou uma das duas irmãs) eram: (1) pedir para abrir a porta de casa, quando chegava do trabalho, embora carregasse consigo a chave, (2) pedir para o familiar abrir e fechar a porta de casa novamente e às vezes falar o nome de uma das suas irmãs, (3) ligar antes do jantar para um de seus familiares e pedir para repetir alguma palavra ou frase para ter uma boa digestão, (4) pedir para o familiar agachar, colocar uma das mãos no chão, completar ou repetir palavras e frases e engolir a saliva, (5) pedir para pegar objetos no chão, em cima da mesa, no varal, etc. Sua mãe (F3) tinha 53 anos no início do estudo, era casada, empregada doméstica, tinha três filhas, sendo as mais velhas gêmeas, ambas portadoras de TOC. A mãe relatou que por 12 anos, diariamente, várias vezes ao dia, atendeu a várias solicitações acima descritas. As recusas da mãe e dos outros familiares de P3 em atender às suas solicitações ocorriam de maneira intermitente, segundo o relato de F3.

\section{Local de coleta}

Os encontros com as familiares e os portadores foram realizados individualmente numa sala do ambulatório do PROTOC. A primeira autora realizou inicialmente dois encontros com os portadores, sendo o primeiro para explicar a pesquisa, fazer a Entrevista Inicial e aplicar a escala YBOCS (descrita a seguir) e o segundo para relatar o encerramento da pesquisa e aplicar novamente a escala $\mathrm{Y}$ BOCS. Os encontros com os familiares foram individuais, semanais, com duração média de 1 h30 cada.

\section{Material}

Foram empregados: 1) Termos de Consentimento Pós-informação do Familiar e do Portador; 2) Roteiro de Entrevista Inicial com o Familiar, elaborado pelas pesquisadoras, para avaliar o desenvolvimento do TOC, a ocorrência dos episódios compulsivos atuais, os tipos de compulsões que mais incomodavam a familiar, a relação da familiar com o portador, as respostas de acomodação da familiar e os efeitos da participação ou não participação da familiar nos episódios compulsivos do portador; 3) Roteiro de Entrevista Inicial com o Portador, elaborado pelas pesquisadoras para identificar as compulsões do portador, as situações mais favoráveis à ocorrência dos episódios compulsivos, as compulsões mais incômodas ao portador, a compulsão com maior ocorrência diária, o impacto dos sintomas compulsivos na dinâmica familiar, especialmente nas respostas de acomodação familiar e avaliar a relação do portador com sua familiar; 4) Escala de Acomodação Familiar - FAS-IR (Gomes et al., 2010) utilizada para avaliar a frequência de participação dos familiares nos sintomas do TOC; 5) Escala de Sintomas Obsessivos-Compulsivos de Yale Brown - Y-BOCS (Goodman et. al., 1989) usada para avaliar a ocorrência e frequência dos sintomas obsessivocompulsivos; 6) Roteiro de Entrevista final com o portador, elaborado pelas pesquisadoras, para avaliação do portador sobre as possíveis mudanças dos comportamentos da familiar, dos efeitos destas mudanças nos seus rituais obsessivocompulsivos e verificar se ele/ela recomendaria a outros familiares de pessoas com TOC, uma intervenção tal qual foi desenvolvida no presente estudo; 7) Registro Diário do Familiar que ocorria numa folha na qual havia espaço para descrever: a) a situação na qual ocorreu o episódio de ritual do portador, apontando quem estava presente; b) as respostas ritualísticas apresentadas pelo portador; c) o comportamento da familiar participante e d) o comportamento subsequente do portador. Esse registro foi utilizado com o objetivo de avaliar as circunstâncias em que ocorriam tanto os episódios ritualísticos do portador quanto as respostas de acomodação da familiar.

As medidas das variáveis dependentes no presente estudo foram a frequência de respostas de acomodação das familiares (F1, F2 e F3) aos episódios de TOC (reais ou virtuais) dos portadores (P1, P2 e P3) e a frequência dos episódios ritualísticos dos portadores.

\section{Procedimento}

No primeiro encontro, a primeira autora explicou às mães que se tratava de uma pesquisa acadêmica cujo objetivo era orientá-las sobre como agir com os portadores diante dos sintomas obsessivo-compulsivos que solicitavam as suas participações e as familiares assinaram um termo de consentimento de participação na pesquisa. No segundo encontro, a pesquisadora aplicou a Escala FAS-IR e comentou que esta escala seria novamente aplicada ao final da pesquisa. Posteriormente, a pesquisadora conversou com cada portador em separado, explicou o objetivo da pesquisa, aplicou a Escala Y-BOCS e informou que ao final da pesquisa esta seria aplicada novamente. Os portadores assinaram um termo de consentimento de participação das familiares na pesquisa.

Pré-intervenção. Em encontros individuais com as mães, a pesquisadora explicou o que é o TOC, os fatores desencadeantes do transtorno e respondeu às dúvidas. Posteriormente, forneceu instruções quanto ao preenchimento do Registro Diário, esclareceu as dúvidas, solicitou que os registros fossem feitos sem que o portador tivesse acesso aos mesmos e que fossem entregues nos encontros semanais.

Intervenção. No primeiro encontro desta fase, a primeira autora explicou para cada mãe o que é acomodação familiar, destacou os efeitos negativos das respostas de acomodação na dinâmica familiar, na vida pessoal das 
familiares e no fortalecimento dos sintomas do TOC. Depois, com base nos registros realizados pelas mães na fase de préintervenção, salientou para cada familiar os tipos mais frequentes de episódios compulsivos apresentados pelos portadores e suas respostas de acomodação. Nos demais encontros dessa fase, solicitou que as mães não participassem de nenhuma maneira de um determinado episódio de TOC. A orientação para que não houvesse acomodação familiar ocorreu de forma hierárquica para os diversos rituais, começando-se pelo episódio de acomodação familiar de menor frequência. A pesquisadora pontuou que posteriormente outras respostas de acomodação seriam abordadas, porém somente quando a primeira classe de respostas fosse eliminada, e assim sucessivamente.

Explicou também que esta nova forma de agir com os portadores poderia provocar inicialmente algumas reações, como irritação, agitação, agressividade, reclamação, chantagem, entre outras. Informou que tais reações teriam sua frequência diminuída com o tempo e que os sintomas obsessivo-compulsivos dos portadores poderiam ter inicialmente sua frequência aumentada, mas, posteriormente, seriam reduzidas, assim como rituais antigos ou novos poderiam surgir neste período.

Também solicitou que as mães dessem atenção (elogios, conversas interessantes aos portadores, atividades em conjunto, expressões afetivas, lazer, etc.) ou fornecessem outros benefícios que agradassem aos portadores (objetos, roupas, presentes, comidas preferida, etc.) quando eles apresentassem qualquer resposta diferente das ritualísticas, na tentativa de instalar e reforçar respostas incompatíveis com estas (DRO).

Com base nos registros trazidos pelas mães, a partir do segundo encontro até o último da fase de Intervenção, a primeira autora realizava, junto com as familiares, uma análise das contingências de reforçamento das respostas envolvidas nos episódios ritualísticos e de suas próprias respostas de acomodação referentes aos sete dias correspondentes à semana anterior. Apontava os estímulos ambientais que poderiam ter a função de estímulos discriminativos para as respostas compulsivas do portador, sinalizando a regularidade destes. Também chamava a atenção para as respostas de acomodação familiar que poderiam ter a função reforçadora das respostas ritualísticas do portador e orientava as familiares sobre como estas deveriam agir diante das reações adversas do portador frente ao procedimento de extinção. Quando o registro indicava que as familiares haviam seguido as instruções, a pesquisadora as elogiava e as incentivava a continuar com esse padrão.

Quando as familiares relatavam dificuldades em seguir as orientações, a pesquisadora procurava fazer uma análise das mesmas e propunha novas estratégias para a solução das dificuldades. No último encontro desta fase, a pesquisadora explicou que os encontros seriam interrompidos por três semanas e que, neste período, não seria necessário que fizessem as anotações no Registro Diário.

Seguimento. Após 21 dias do último encontro com as mães, a pesquisadora pediu que elas fizessem novamente os registros diários por uma semana. No último encontro com a díade, a pesquisadora recolheu os registros diários e aplicou novamente a Escala FAS-IR nas mães, a Escala Y-BOCS nos portadores e, na sequência, uma entrevista final com os portadores sem a presença das familiares.

\section{RESULTADOS}

A seguir serão apresentados para cada díade os dados referentes aos episódios ritualísticos dos portadores de TOC e as respostas de acomodação de suas mães a partir dos registros diários realizados pelas familiares nas fases de Préintervenção, Intervenção e Seguimento.

A primeira autora analisou as classes de respostas de acomodação das mães a partir de todos os registros realizados por elas e solicitou a um observador independente que analisasse uma amostra de $30 \%$ desses registros, chegando-se a $90,6 \%$ de acordo.

Díade 1. Na Pré-intervenção, F1 realizou 13 registros diários, nos quais anotou 65 episódios ritualísticos de P1 e 283 episódios de acomodação familiar. Na fase de Intervenção, F1 realizou 56 registros diários durante oito semanas nos quais anotou 91 episódios ritualísticos de P1 e 448 episódios de acomodação familiar. No Seguimento, não houve episódios ritualísticos, nem de acomodação familiar.

A Tabela 1 apresenta as médias diárias da frequência das respostas ritualísticas de P1 e das respostas de acomodação familiar de F1, calculadas em cada encontro semanal das fases Pré-intervenção, Intervenção e Seguimento.

Na fase de Pré-intervenção houve quatro encontros. No entanto, a mãe só conseguiu realizar o registro corretamente nas duas últimas semanas desta fase. A Tabela 1 permite observar que a diminuição na frequência diária das respostas de acomodação da mãe acompanhou a diminuição dos episódios ritualísticos da filha. Como se pode ver, a média diária de episódios ritualísticos apresentados por P1 na fase de Pré-intervenção variou entre 0,3 e 4,0 e a média diária das respostas de acomodação de F1 variou entre 0,3 e 7,8. Na fase de Intervenção a mãe deixou de apresentar as respostas de acomodação familiar, uma por vez. De acordo com F1, deixar de "guardar a louça em local diferente", ficou por último, uma vez que sua filha reagiu muito mal à recusa da mãe em atender a sua solicitação. Na última semana de Intervenção, ocorreu uma redução na frequência desta resposta, porém a eliminação somente ocorreu após o término da fase de Intervenção, mantendo-se dessa forma, assim como as demais respostas de acomodação de F1 e ritualísticas de P1, na fase de Seguimento. 
Tabela 1

Médias Diárias das Frequências das Respostas de P1 e F1 Analisadas em cada Encontro Semanal das Fases de Pré-Intervenção, Intervenção e Seguimento.

\begin{tabular}{|c|c|c|c|c|c|c|c|c|c|c|c|}
\hline \multirow{3}{*}{ Classe de Respostas Ritualísticas de P1 } & \multicolumn{2}{|c|}{$\underline{\text { Pré-interv. }}$} & \multirow{3}{*}{$1^{\circ}$} & \multirow{3}{*}{$2^{\circ}$} & \multicolumn{3}{|c|}{$\underline{\text { Intervenção }}$} & \multirow{3}{*}{$6^{\circ}$} & \multirow{3}{*}{$7^{\circ}$} & \multirow{3}{*}{$8^{\circ}$} & \multirow{3}{*}{$\frac{\text { Seg. }}{1^{\circ}}$} \\
\hline & $1^{\mathrm{o}}$ & $2^{\circ}$ & & & $3^{\circ}$ & $4^{\circ}$ & $5^{\circ}$ & & & & \\
\hline & & & & & & & & & & & \\
\hline Pede para a mãe lavar a roupa & 0,3 & 0,3 & 0,1 & 0 & 0 & 0 & 0 & 0 & 0 & 0 & 0 \\
\hline Pede para a mãe preparar o almoço e/ou jantar & 0,8 & 0,6 & 0,6 & 0 & 0 & 0 & 0 & 0 & 0 & 0 & 0 \\
\hline Pede para a mãe pegar, guardar bebida e comida na geladeira & 4,0 & 3,9 & 3,0 & 2,9 & 2,7 & 2,7 & 1,0 & 0 & 0 & 0 & 0 \\
\hline Classe de Respostas de Acomodação Familiar de F1 & & & & & & & & & & & \\
\hline Lava a roupa da filha separado das roupas da família & 0,3 & 0,3 & 0 & 0 & 0 & 0 & 0 & 0 & 0 & 0 & 0 \\
\hline Prepara o almoço e/ou jantar com panela separada & 0,8 & 0,6 & 0,6 & 0 & 0 & 0 & 0 & 0 & 0 & 0 & 0 \\
\hline Lava louça com bucha separada & 4,0 & 4,0 & 1,0 & 0 & 0 & 0 & 0 & 0 & 0 & 0 & 0 \\
\hline Guarda a louça em local diferente & 4,0 & 4,0 & 3,7 & 3,9 & 3,7 & 3,7 & 3,7 & 3,7 & 3,7 & 2,7 & 0 \\
\hline Retira louça da mesa e coloca em cima da pia & 4,0 & 4,0 & 3,7 & 3,9 & 1,4 & 0 & 0 & 0 & 0 & 0 & 0 \\
\hline Pega e guarda bebida e comida na geladeira & 7,8 & 7,7 & 6,0 & 5,7 & 5,4 & 2,0 & 0 & 0 & 0 & 0 & 0 \\
\hline
\end{tabular}

A aplicação da Escala FAS-IR (com um máximo de 48 pontos) mostrou uma redução na pontuação de 34 (no início do estudo) para 15 (no seu final), o que indica uma diminuição na acomodação familiar. Os 15 pontos finais estavam associados à ocorrência de comportamentos de observação dos rituais da filha, os quais não foram abordados neste estudo. A Escala Y-BOCS aplicada em P1 ao final da pesquisa indicou que a pontuação para Obsessões se manteve a mesma daquela obtida antes da Intervenção (11 pontos com um máximo de 20 pontos) e a pontuação para Compulsão aumentou de 9 para 10 pontos (máximo de 20 pontos). $\mathrm{Na}$ entrevista final P1 relatou ter ficado satisfeita com os resultados das mudanças ocorridas na sua relação com a mãe, tendo adquirido mais independência. Porém, relatou também ter ficado muito ansiosa com as mudanças de comportamento da mãe, tendo aumentado a frequência das compulsões que não envolviam a participação dessa familiar e desenvolvido um novo ritual relacionado à resposta "abrir a geladeira para pegar alimentos".

A análise das respostas ritualísticas de P1 indicou que apenas a classe de respostas "pedir para a mãe pegar bebida e comida na geladeira" correspondia a uma solicitação atual de participação da mãe num episódio ritualístico. As respostas "pedir para a mãe lavar suas roupas" e "preparar suas refeições" pareciam estar sendo mantidas por contingências de reforçamento ocorridas no passado, uma vez que a mãe lavava as roupas da filha separadamente das demais roupas da família e cozinhava os alimentos para ela em panela separada das demais, sem que a filha lhe pedisse. Tais pedidos foram feitos no passado e a mãe mantinha as respostas de acomodação. O mesmo ocorreu com a classe de respostas de acomodação "lavar a louça com bucha separada", "guardar a louça em local diferente" e "retirar a louça da mesa e colocar em cima da pia”. P1 não mais solicitava que sua mãe apresentasse tais classes de respostas, porém como a filha havia solicitado no passado, a mãe continuou a apresentar esses comportamentos por sete anos.

Díade 2. Na Pré-intervenção, F2 realizou 23 registros diários, nos quais anotou 66 episódios ritualísticos e 64 episódios de acomodação familiar. $\mathrm{Na}$ fase de Intervenção, F2 realizou 56 registros diários durante oito semanas, nos quais anotou 111 episódios ritualísticos de P2 e 68 episódios de acomodação familiar. No Seguimento, apenas dois episódios de acomodação foram mantidos, e outros dois episódios eliminados.

A Tabela 2 apresenta as médias diárias da frequência das respostas ritualísticas de $\mathrm{P} 2$ e das respostas de acomodação familiar de F2 calculadas em cada encontro semanal das fases Pré-intervenção, Intervenção e Seguimento.

Para essa familiar foram necessárias cinco semanas de Pré-intervenção, devido às dificuldades de registrar apresentadas por ela, tendo ocorrido vários dias sem registro.

A Tabela 2 mostra que tanto a média diária de episódios ritualísticos apresentados por P2 quanto a média diária das respostas de acomodação de F2 na Préintervenção variaram entre zero e 2,7. Na fase de Intervenção, dois comportamentos que compunham os episódios ritualísticos diminuíram de frequência, a saber, "conversar com a mãe para assegurar seus pensamentos obsessivos" e "pedir para mãe dormir com ele no mesmo quarto ou colchão" e mantiveram-se eliminados na fase de Seguimento. 
Tabela 2

Médias Diárias das Frequências das Respostas de P2 e F2 Analisadas em cada Encontro Semanal das Fases de Pré-Intervenção, Intervenção e Seguimento.

\begin{tabular}{|c|c|c|c|c|c|c|c|c|c|c|c|c|c|c|}
\hline \multirow[b]{3}{*}{ Classe de Respostas Ritualísticas de P2 } & \multicolumn{5}{|c|}{$\underline{\text { Pré-interv. }}$} & \multicolumn{8}{|c|}{$\underline{\text { Intervenção }}$} & \multirow{3}{*}{$\underline{\mathrm{Se}}$} \\
\hline & $1^{\circ}$ & $2^{\circ}$ & $3^{\circ}$ & $4^{\circ}$ & $5^{\circ}$ & $1^{\circ}$ & $2^{\circ}$ & $3^{\circ}$ & $4^{\circ}$ & $5^{\circ}$ & $6^{\circ}$ & $7^{\circ}$ & $8^{\circ}$ & \\
\hline & & & & & & & & & & & & & & \\
\hline Conversa com a mãe para reassegurar seus pensamentos obsessivos & 0,2 & 0,3 & 0,2 & 0,3 & 0 & 0 & 0 & 0 & 0 & 0 & 0 & 0 & 0 & 0 \\
\hline Abraça, beija e senta no colo da mãe & 0,7 & 0,3 & 1,0 & 0,8 & 0,4 & 1,1 & 0,8 & 0,1 & 0 & 0 & 1,1 & 0,4 & 0,6 & 0,4 \\
\hline Pede para a mãe dormir com ele no mesmo quarto ou colchão & - & - & - & 0,3 & 1,0 & 1,0 & 0,7 & 0 & 0 & 0 & 0 & 0 & 0 & 0 \\
\hline Pergunta a mãe se ela está bem & 0,2 & 0,7 & 1,6 & 2,7 & 2,2 & 2,0 & 1,8 & 2,3 & 0,8 & 1,0 & 0,3 & 0,3 & 1,3 & 0,4 \\
\hline \multicolumn{15}{|l|}{ Classe de Respostas de Acomodação Familiar de F2 } \\
\hline Conversa com o filho para acalmá-lo diante das obsessões & 0,2 & 0,3 & 0,2 & 0,3 & 0 & 0 & 0 & 0 & 0 & 0 & 0 & 0 & 0 & 0 \\
\hline Abraça, beija e coloca o filho no colo & 0,7 & 0,3 & 0,8 & 0,8 & 0,2 & 0,8 & 0,3 & 0,1 & 0 & 0 & 0,4 & 0,1 & 0,4 & 0,4 \\
\hline Dorme com o filho no mesmo quarto ou colchão & - & - & - & 0,3 & 1,0 & 0,8 & 0,6 & 0,6 & 0 & 0 & 0 & 0 & 0 & 0 \\
\hline Responde ao filho que está bem & 0,2 & 0,7 & 1,6 & 2,7 & 2,2 & 1,4 & 1,6 & 0,4 & 0,1 & 0,1 & 0,1 & 0,3 & 1,3 & 0,4 \\
\hline
\end{tabular}

Com relação ao episódio ritualístico "abraçar, beijar e sentar no colo da mãe", a Tabela 2 mostra uma frequência variável na fase de Intervenção, ocorrendo com frequência zero apenas nos registros relativos aos quarto e quinto encontros dessa fase. $\mathrm{Na}$ fase de Seguimento este comportamento ocorreu com uma frequência média diária de 0,4. "Perguntar a mãe se ela está bem" persistiu na fase de Intervenção numa frequência diária que variou entre 0,3 e 2,3 e ocorreu com uma média diária de 0,4 na fase de Seguimento.

$\mathrm{Na}$ Tabela 2, nota-se também que as duas respostas de acomodação de $\mathrm{F} 2$ que não foram suprimidas, citadas anteriormente, são aquelas correspondentes aos episódios ritualísticos de P2 que persistiram durante todo o estudo. A aplicação da Escala FAS-IR no final e no início do estudo indicou uma redução de 36 para 9 pontos compatível com uma diminuição na acomodação familiar. A Escala Y-BOCS aplicada em P2 indicou que houve aumento nos escores obtidos no final da pesquisa em relação à primeira aplicação tanto para Obsessões (aumentou de 11 para 14 pontos) quanto para Compulsões (aumentou de seis para 12 pontos), sugerindo uma piora nos sintomas do TOC, apesar da redução na acomodação familiar detectada pela escala FAS-IR. Na entrevista final P2 relatou ter sofrido muito com as mudanças de comportamento da mãe, dizendo estar mais ansioso e angustiado com pensamentos obsessivos de que estava "sendo punido por Deus por realizar as trocas envolvendo a vida de familiares". Por outo lado, no final do estudo P2 relatou sentir-se mais seguro e independente, tendo aprendido a controlar mais suas necessidades de auxílio da mãe e realizando atividades que antes só conseguia fazer na companhia dela como ligar para marcar consulta, ir aos médicos e dormir sozinho.

Os dados indicaram que as quatro classes de respostas de acomodação de F2 focadas no presente estudo eram apresentadas em resposta às solicitações de P2. Pode-se supor que respostas de P2 eram desencadeadas por suas respostas encobertas (pensamentos obsessivos) em situações de dificuldades pessoais, de cansaço físico e quando a mãe demonstrava tristeza e desânimo, provavelmente relacionados à morte recente do marido. F2 relatou que percebia que seu filho parecia ficar tranquilo quando ela atendia suas solicitações. Importante ressaltar que um dos pensamentos obsessivos de $\mathrm{P} 2$, relatado pela mãe, era de que ele fazia trocas com Deus para conseguir o que desejava, oferecendo a vida de um de seus familiares. Esta compulsão também ocorreu no dia do falecimento de seu pai, gerando, segundo sua mãe, um agravamento no quadro clínico de P2 e uma maior dependência, podendo justificar a dificuldade de F2 em seguir as instruções da pesquisadora para não atender às solicitações do filho.

Díade 3. Na Pré-intervenção, F3 realizou 25 registros diários, nos quais anotou 79 episódios ritualísticos e 79 episódios de acomodação familiar. $\mathrm{Na}$ fase de Intervenção, F3 realizou 63 registros diários durante nove semanas nos quais anotou 76 episódios ritualísticos e 70 episódios de acomodação familiar. No Seguimento, não houve episódios ritualísticos, nem de acomodação familiar.

A Tabela 3 apresenta as médias diárias da frequência das respostas ritualísticas de P3 e das respostas de acomodação familiar de F3, calculadas em cada encontro semanal das fases Pré-intervenção, Intervenção e Seguimento. 
Tabela 3

Médias Diárias das Frequências das Respostas de P3 e F3 Analisadas em cada Encontro Semanal das Fases de Pré-Intervenção, Intervenção e Seguimento.

\begin{tabular}{|c|c|c|c|c|c|c|c|c|c|c|c|c|c|c|}
\hline \multirow{3}{*}{ Classe de Respostas Ritualísticas de P3 } & \multicolumn{4}{|c|}{ Pré-interv. } & \multicolumn{9}{|c|}{$\underline{\text { Intervenção }}$} & \multirow{3}{*}{$\frac{\text { Seg. }}{1^{\circ}}$} \\
\hline & $1^{\circ}$ & $2^{\circ}$ & $3^{\circ}$ & $4^{\circ}$ & $1^{\circ}$ & $2^{\circ}$ & $3^{\circ}$ & $4^{\circ}$ & $5^{\circ}$ & $6^{\circ}$ & $7^{\circ}$ & $8^{\circ}$ & $9^{\circ}$ & \\
\hline & & & & & & & & & & & & & & \\
\hline Pede para abrir e fechar a porta de casa, quando chega do trabalho & 0 & 0,2 & 0,1 & 0,2 & 0 & 0 & 0 & 0 & 0 & 0 & 0 & 0 & 0 & 0 \\
\hline Pede para abrir e fechar a porta novamente & 0 & 0,2 & 0,1 & 0 & 0,1 & 0,3 & 0 & 0 & 0 & 0 & 0 & 0 & 0 & 0 \\
\hline Pede para pegar objetos no chão, da mesa, varal, parede, etc. & 0,1 & 0 & 0,7 & 0 & 0 & 0,1 & 0 & 0,1 & 0 & 0 & 0 & 0 & 0 & 0 \\
\hline Pede para fazer rituais verbais e/ou gestuais por telefone ou pessoalmente & 2,3 & 1,2 & 0,4 & 3,8 & 3,0 & 3,0 & 1,9 & 1,0 & 0,8 & 0,4 & 0,3 & 0,1 & 0 & 0 \\
\hline Classe de Respostas de Acomodação Familiar de F3 & & & & & & & & & & & & & & \\
\hline Abre e fecha a porta de casa, quando $\mathrm{P} 3$ chega do trabalho & 0 & 0,2 & 0,1 & 0,2 & 0 & 0 & 0 & 0 & 0 & 0 & 0 & 0 & 0 & 0 \\
\hline Abre e fecha a porta de casa novamente & 0 & 0,2 & 0,1 & 0 & 0,3 & 0 & 0 & 0 & 0 & 0 & 0 & 0 & 0 & 0 \\
\hline Pega objetos no chão, na mesa, varal, parede, etc. & 0,1 & 0 & 0,7 & 0 & 0 & 0,1 & 0 & 0 & 0 & 0 & 0 & 0 & 0 & 0 \\
\hline Faz rituais verbais e/ou gestuais por telefone ou pessoalmente & 2,3 & 1,2 & 0,4 & 3,8 & 3,0 & 2,9 & 1,9 & 0,7 & 0,4 & 0,4 & 0,3 & 0 & 0 & 0 \\
\hline
\end{tabular}

A Tabela 3 mostra que a média diária de episódios ritualísticos apresentados por P3 na fase Préintervenção variou entre 0,0 e 3,8, e as médias diárias das respostas de acomodação de F3, nesta mesma fase, foram idênticas àquelas dos episódios ritualísticos de $\mathrm{P} 3$, o que significa que $\mathrm{F} 3$ atendeu todos os pedidos da filha. Na fase de Intervenção, houve uma redução na frequência média diária para três das quatro respostas de acomodação de F3 que parece ter sido acompanhada pela redução dos episódios ritualísticos de P3. Pode-se ver também na Tabela 3 que nenhuma resposta de acomodação de F3 e nenhum episódio ritualístico de P3 ocorreu na fase de Seguimento. Chama a atenção o fato de que na fase de Intervenção, a resposta de acomodação correspondente ao episódio ritualístico "fazer rituais verbais e/ou gestuais por telefone ou pessoalmente" foi tendo sua frequência reduzida gradativamente. Esta classe de respostas era aquela de maior frequência diária na fase Pré-intervenção, portanto, potencialmente a mais difícil de ser extinta e a última a ser eliminada na fase de Intervenção. Foi proposto a F3 que fizesse uma redução gradativa dessa classe de respostas (fading-out) a partir da terceira semana da Intervenção, devido aos prováveis efeitos colaterais do procedimento de extinção.

A aplicação da Escala FAS-IR indicou uma redução de 34 para 12 pontos, sugerindo uma diminuição na acomodação familiar. Os 12 pontos finais estavam associados à ocorrência de comportamentos como assistir os rituais da filha, tolerar comportamentos estranhos, conter-se para não dizer nada relacionado às obsessões da filha, os quais não foram abordados neste estudo. A aplicação da Escala Y-BOCS em P3 mostrou que houve diminuição tanto na pontuação para as Obsessões ao final da pesquisa com relação à primeira aplicação (16 para 10 pontos) quanto na pontuação para Compulsões (de 15 para 10 pontos), indicando uma melhora nos sintomas do TOC. Apesar disso, na entrevista final $\mathrm{P} 3$ relatou que não ficou feliz com o resultado da intervenção, pois sua mãe passou a não atender mais suas solicitações ritualísticas. Também disse ter sofrido bastante com as mudanças de comportamento da mãe, sentindo mais ansiedade, angústia e irritabilidade.

Os dados obtidos pelos registros de F3 sugeriram que as quatro classes de respostas de acomodação focadas no presente estudo eram apresentadas sempre em resposta às solicitações de P3. Tais respostas devem ter sido instaladas no passado, sendo provavelmente mantidas por contingências de reforçamento negativo, uma vez que P3 apresentava reações hostis e agressivas quando a mãe se recusava a atender suas solicitações. De acordo com o relato de F3, durante a fase de Intervenção a filha apresentou comportamentos agressivos dirigidos aos seus familiares como chutar a porta do quarto dos pais, gritar, ofender, fazer chantagens e greve de fome. Além dessas respostas, houve o aumento na frequência diária das compulsões que não envolviam a participação de F3 e o surgimento de novos rituais relacionados ao enfrentamento da eliminação das respostas de acomodação.

\section{DISCUSSÃO}

Dados da literatura sobre acomodação familiar têm apontado que a ocorrência deste fenômeno produz intenso sofrimento nas famílias (Ramos-Cerqueira et al., 2008, Ferrão \& Florão, 2010) e pode contribuir para a evolução acentuada dos sintomas obsessivos-compulsivos (Gomes et al., 2014, Thompson-Hollands et al., 2015). A Intervenção dirigida apenas às mães de portadores de TOC no presente estudo envolveu fornecimento de informação sobre o distúrbio, sobre a acomodação familiar e seus possíveis efeitos, uma análise das contingências de reforçamento das respostas ritualísticas e das respostas de acomodação a partir dos registros diários realizados por elas, instruções para que as familiares deixassem de apresentar as respostas de acomodação, a previsão de possíveis reações dos portadores diante da suspensão do reforçamento, treino de habilidades para a resolução das 
dificuldades e reforçamento social para o seguimento de instruções.

Os resultados da presente pesquisa indicam que uma intervenção dirigida apenas às mães foi capaz de reduzir a acomodação familiar e essa redução foi acompanhada por um enfraquecimento das respostas ritualísticas dos portadores de TOC que solicitavam a participação da familiar. No entanto, novos episódios ritualísticos surgiram, o que talvez pudesse ser evitado se tivessem ocorrido intervenções dirigidas também aos portadores do distúrbio, conforme sugerem alguns autores (Tompson-Hollands et al., 2015).

A aplicação dos critérios apresentados por Baer, Wolf e Risley (1968, 1987) para avaliar uma pesquisa aplicada em Análise do Comportamento indica que a mesma (1) atendeu o critério de uma pesquisa aplicada, uma vez que os comportamentos-alvo foram escolhidos devido à sua importância para as díades participantes; (2) preencheu parcialmente o critério comportamental, tendo sido feita uma análise funcional das classes de respostas de acomodação das participantes registradas pelas mesmas, mas não uma avaliação da integridade dos procedimentos utilizados pelas mãe, nem uma observação direta dos comportamentos da díade; (3) preencheu o critério analítico ao utilizar o delineamento de sujeito como seu próprio controle, que permitiu revelar as possíveis variáveis responsáveis pela ocorrência e manutenção das respostas de acomodação e das respostas ritualísticas; (4) empregou e descreveu completamente as técnicas comportamentais como DRO, modelagem, análise funcional da relação das familiares com os portadores, análise das contingências de classe de respostas de acomodação e ritualística dos portadores e reforçamento social das respostas das mães, atingindo o critério tecnológico; (5) empregou técnicas compatíveis com os princípios da Análise do Comportamento atendendo o critério conceitual; (6) mostrou-se parcialmente eficaz, tendo os próprios participantes avaliado uma redução na acomodação familiar, embora tenham também relatado o surgimento de novos rituais obsessivos-compulsivos e aumento de ansiedade no decorrer do procedimento e (7) preencheu o critério generalizável ao observar a manutenção da mudança comportamental das participantes 21 dias após o término da intervenção.

\section{DECLARAÇÃO DE CONFLITO DE INTERESSES}

As autoras declaram que não há qualquer conflito de interesses relativos à publicação deste artigo.

\section{CONTRIBUIÇÃO DE CADA AUTORA}

Certificamos que ambas as autoras participaram suficientemente do trabalho para tornar pública sua responsabilidade pelo conteúdo. A contribuição de cada autora pode ser atribuída como se segue: Lilian Boarati e Fani E. K. Malerbi contribuíram para a concepção do artigo; foram responsáveis pelo planejamento da pesquisa e pela redação final; Lilian Boarati fez a coleta de dados; Fani E K Malerbi e Lilian Boarati foram responsáveis pela redação final.

\section{DIREITOS AUTORAIS}

Este é um artigo aberto e pode ser reproduzido livremente, distribuído, transmitido ou modificado, por qualquer pessoa desde que usado sem fins comerciais. $\mathrm{O}$ trabalho é disponibilizado sob a licença Creative Commons 4.0 BY-NC.

\section{$(\mathrm{cc}) \mathrm{BY}-\mathrm{NC}$}

\section{REFERÊNCIAS}

Albert, U., Bogetto, F., Maina, G., Saracco, P., Brunatto, C., \& Mataix, D. C. (2010). Family accommodation in obsessive-compulsive disorder: relation to symptom dimension, clinical and family caracteristics. Psychiatry Research, 179, 204-211. doi: 10.1016/j.psychres.2009.06.008.

American Psychiatric Association (2014). DSM -5. Manual de diagnóstico e estatístico das perturbações mentais. $5^{\mathrm{a}}$ Edição. Lisboa: Climepsi Editores.

Baer, D. M., Wolf, M. M., \& Risley, T. R. (1968). Some current dimensions of applied behavior analysis. Journal of Applied Behavior Analysis, 1(1), 91-97. doi: 10.1901/jaba.1968.1-91

Baer, D. M., Wolf, M. M., \& Risley, T. R. (1987). Some still-current dimensions of applied behavior analysis. Journal of Applied Behavior Analysis, 20(4), 313-327. doi: 10.1901/jaba.1987.20-313

Calvocoressi, L., Lewis, B., Harris, M., Trufan, S. J., Goodman, W. K., Mc Dougle, C. J., \& Price, L. H. (1995). Family accommodation in obsessivecompulsive disorder. American Journal of Psychiatry, 152, 441-443. doi: 10.1176/ajp.152.3.441

Cooper, M. (1996). Obsessive-compulsive disorder: effects on family members. American Journal of Othopsychiatry, 66, 296-304. doi: 10.1037/h0080180

Ferrão, Y. A., \& Florão, M. S. (2010). Acomodação familiar e criticismo percebido em pacientes com transtorno obsessivo-compulsivo. Jornal Brasileiro de Psiquiatria, 59(1), 34-43. doi: 10.1590/S004720852010000100006

Gomes, J. B., Meyer, C. M., Braga, D., Kristensen, C., \& Cordioli, A. (2010). Translation and adaptation into Brazilian Portuguese of family accommodation scale for obsessive-compulsive disorder: interviewer-rated (FAS-IR). Revista de Psiquiatria do Rio Grande do Sul, 32(3), 102-112. doi: 10.1590/S010181082010000300007

Gomes, J. B., Van Noppen, B. V., Pato, M., Braga, D. T., Meyer, E., Bortoncello, C. F., \& Cordioli, A. V. (2014). Patient and family factors associated with family accommodation in obsessive-compulsive disorder. Psychiatry and Clinical Neurosciences, 68 (8), 621-630. doi: 10.1111/pcn.12172

Goodman, W. K., Price, L. H., Rasmussen, S. A., Mazure, C., Fleischmann, R. L., Hill, C. L., Heninger, G. R., \& Charney, D. S. (1989). The Yale-Brown obsessive compulsive scale. I Development, use, and reliability. Archives of General Psychiatry, 46, 1006-1011. doi:10.1001/archpsyc.1989.01810110048007

Guedes, M. L. (2001). Relação família-paciente no transtorno obsessivo-compulsivo. Revista Brasileira de 
Psiquiatria, 23, II, 65-7. doi: 10/1590/S15164446200100006000019

Guedes, M. L. (1997). Transtorno obsessivo-compulsivo: um estudo do processo de acomodação familiar. Dissertação de Mestrado. Universidade Federal de São Paulo, São Paulo.

Murray-Swank, A. B., \& Dixon, L, (2004). Family psychoeducation as an evidence-based practice. CNS Spectrums, $9, \quad 905-912 . \quad$ doi: 10.1017/S109285290000972X

O’Connor, K. P., Aardema, F., Robillard, S., Guay, S., Pélissier, M. C., Todorov, C., Borgeat, F., Leblanc V., Grenier, S., Doucet, P. (2006). Cognitive behaviour therapy and medication in the treatment of obsessivecompulsive disorder. Acta Psychiatry Scand, 113(5), 408-419. doi: 10.1111/j.1600-0447.2006.0076.x

Oliveira, A. G., Silva, J. F., Teles, L. C., \& Machado, R. M. (2012). Caracterização dos pacientes com transtorno obsessivo-compulsivo: um estudo epidemiológico. Cogitare Enfermagem, 17(4), 676682. doi: http://dx.doi.org/10.5380/ce.v17i4.30365

Organização Mundial da Saúde (1997). CID10 Classificação Estatística Internacional de Doenças e Problemas Relacionados à Saúde. 10a rev. São Paulo: Universidade de São Paulo.

Pardue, C. M., Sibrava, N. J., Boisseau, C., Mancebo, M. C., Eisen, J. L., \& Rasmussen, S. A. (2014). Differential parental influence in the familial aggregation of obsessive-compulsive disorder. Journal of Obsessive-Compulsive and Related Disorders, 3, 215-219. doi: 10.1016/j.jocrd.2014.05.001

Ramos-Cerqueira, A. T., Torres, A. R., Torresan, R. C., Negreiros, A. P., \& Vitorino, C. N. (2008). Emotion burden in caregivers of patients with obsessivecompulsive disorder. Depression and Anxiety. The official journal of ADAA, 25, 1020-1027. doi: 10.1002/da.20431

Renshaw, K. D., Steketee, G., \& Chambless, D. L. (2005). Involving family members in the treatment of OCD. Cognitive Behavior Therapy, 34(3), 164-175. doi: 10.1080/16506070510043732

Skinner, B. F. (2000). Ciência e comportamento humano. São Paulo: Martins Fontes. Trabalho originalmente publicado em 1953.

Skinner, B. F. (1992). Sobre o behaviorismo. São Paulo: Cultrix. Trabalho originalmente publicado em 1974.

Steketee, G. (1997). Disability and family burden in obsessive-compulsive disorder. Canadian Journal of Psychiatry, 42(9), 919-28. doi: 10.1177/070674379704200902

Steketee, G., \& Van Noppen, B. (2003). Family approaches to treatment for obsessive-compulsive disorder. Revista Brasileira de Psiquiatria, 25(1), 4350. doi: 10.1590/S1516-44462003000100009

Thompson-Hollands, J., Abramovitch, A., Tompson, M. C., \& Barlow, D. H. (2015). A randomized clinical trial of a brief family intervention to reduce accommodation in obsessive-compulsive disorder: a preliminar study. Behavior Therapy, 46(2), 218-229. doi: 10.1016/j.beth.2014.11.001
Torres, A. R., Shavitt, R. G., Miguel, E. C., Rosario, M. C., Mathis, M. A., Braga, D. T., Chacon, P., Fontenelle, L. F., Gonzalez, C. H., Hoexter, M. Q., Hounie, A. G., Mastrorosa, R. S., Perin, E. A., Petribu, K., Prado, H., Quarintini, L., Velloso, P., \& Andrada, N. C. (2011). Transtorno obsessivo compulsivo: tratamento. Associação Médica Brasileira e Agência Nacional de Saúde. Diretrizes Clínicas na Saúde Suplementar recuperado em 14 de dezembro de 2018 de https://docplayer.com.br/8387161-Autoriaassociacao-brasileira-de-psiquiatria.html

Wielenska, R, C. (2001). Terapia comportamental do transtorno obsessivo compulsivo. Revista Brasileira de Psiquiatria, 23, II, 62-4. doi: 10.1590/S151644462001000600018

Submetido em: 10/08/2018 Aceito em: 27/12/2018 